\title{
Knowledge, Attitude and Practice of Medication Therapy Management among Hospital Pharmacists in Delta State, Nigeria
}

\section{Akonoghrere Rita ${ }^{1 *}$, Aghoja Ogheneovo ${ }^{1}$, Adje David ${ }^{1}$, Ogbonna Brian $^{3}$, Oparah Azuka ${ }^{2}$ and Nwachukwu Angel ${ }^{4}$}

${ }^{1}$ Department of Clinical Pharmacy and Pharmacy Administration, Faculty of Pharmacy, Delta State University Abraka, Nigeria

${ }^{2}$ Department of Clinical Pharmacy and Pharmacy Practice, Faculty of Pharmacy, University of Benin, Nigeria

${ }^{3}$ Department of Clinical Pharmacy, Faculty of Pharmacy, Nnamdi Azikiwe University, Nigeria

${ }^{4}$ Central Hospital Warri, Delta State, Nigeria

*Corresponding Author: Akonoghrere Rita, Department of Clinical Pharmacy and Pharmacy Administration, Faculty of Pharmacy, Delta State University Abraka, Nigeria.
Received: June 03, 2020

Published: July 31, 2020

(C) All rights are reserved by Akonoghrere

Rita., et al.

\section{Abstract}

Medication Therapy Management (MTM) service provided by pharmacists aims at optimizing drug therapy and improving therapeutic outcomes for patients. The objective of this study was to assess the knowledge, attitude and practice of MTM among hospital pharmacists in Delta State Nigeria. The study was a cross-sectional, descriptive survey. Overall, 115 copies of a validated 20 item questionnaire were distributed to hospital pharmacists in major towns in Delta state. Verbal consent was obtained from the respondents prior to administering the questionnaire. The filled questionnaires were collected, sorted and analysed. A total of 100 pharmacists participated in the study, of which 52 were females. The response rate was $86.96 \%$; $94 \%$ of the respondents had a good knowledge of MTM. Most of the respondents felt that MTM encourages collaboration and cooperation between pharmacists and other health care professionals (95\%), while 97\% were willing to promote MTM in their hospital pharmacies. A total of 89 respondents use MTM tools to communicate and collaborate with other health care professionals to achieve optimal treatment outcomes. In conclusion, majority of the pharmacists had good knowledge of MTM, were willing to promote MTM and a few have started providing the service. Keywords: Pharmacy Practice; Hospital Pharmacists' Services; Nigeria, Medication Therapy Management; Medication Reconciliation; Pharmaceutical Care

\section{Introduction}

Medication Therapy Management (MTM) has been described as "the distinct service or group of services that optimise therapeutic outcomes for individual patients that are independent of, but can occur in conjunction with, the provision of a drug product" [1]. MTM is the current term that represents a suite of health care services that have evolved out of the philosophy and processes described in the early 1990s by Strand as "pharmaceutical care" (Pel- legrino., et al. 2009). Hepler and Strand [2] published the paper on Pharmaceutical Care that changed the direction of pharmacy practice worldwide. They defined pharmaceutical care as "the responsible provision of drug therapy for the purpose of achieving definite outcomes that improve a patient's quality of life". The outcomes include curing a disease, eliminating or reducing symptoms, arresting or slowing a disease process and preventing a disease or symptoms. To achieve these ends, pharmacists cooperate with patients 
and with other health care professionals in designing, implementing and monitoring a care plan aimed at preventing and resolving drug-related problems [3]. Medication Therapy Management, also referred to as MTM, is the care provided by pharmacists whose aim is to optimize drug therapy and improve therapeutic outcomes for patients. The pharmacist checks regularly with the patient; ensures he/she is taking medications as prescribed; verifies the patient is following health and wellness guidelines; and checks for medication related problems. Through these services, a pharmacist keeps in touch with other healthcare providers, such as the physicians and nurses, bridging the gap and keeping track of every aspect of a patient's health [4]. These services include a broad range of professional activities, including but not limited to performing patient assessment and/or a comprehensive medication review, formulating a medication treatment plan, monitoring efficacy and safety of medication therapy, enhancing medication adherence through patient empowerment and education, documenting and communicating Medication Therapy Management services to prescribers in order to maintain comprehensive patient care [5].

Medication Therapy Management is a unique niche for the pharmacy profession, allowing pharmacists to apply their knowledge as medication experts with the intent of improving patient outcomes. Also, MTM services empower patients to take an active role in managing their medications. The services are dependent upon pharmacists working collaboratively with physicians and other healthcare professionals to optimize medication use in accordance with evidence based guidelines [6]. They are distinct from medication dispensing, being patient-centred rather than product-centred care; they help to address the urgent public health need for the prevention of medication-related morbidity and mortality; may contribute to medication error prevention, and enable patients to take an active role in medication and healthcare self-management. Medication Therapy Management services also enhance patients' understanding of appropriate drug use, increase adherence to medication therapy, and improve detection of adverse drug events. In general, MTM programs are demonstrating positive clinical, economic and humanistic outcomes across diverse patient populations in various patient care settings [7]. Any patient who uses prescription and non-prescription medications, herbal products, or other dietary supplements could potentially benefit from the MTM core elements. As part of the effort to effectively address the urgent public health issue of medication-related morbidity and mortality, these services should be considered for any patient with actual or potential medication-related problems, regardless of the number of medications they use, their specific disease states, or their health plan coverage.

During the MTM session, the pharmacist identifies medicationrelated problem(s). Following the patient encounter and/or intervention, the pharmacist must document his/her encounter and determine appropriate patient follow-up [8]. The evolution from pharmaceutical care research interventions to large-scale Medication Therapy Management programs in routine practice represents a journey involving multiple practice settings, patient populations, and intervention components and features. The potential for improvement in quality of life and in cost reduction is great, herein lies the importance of providing Medication Therapy Management services.

Over time, standards for services in routine hospital pharmacy practice have evolved, focusing on services based on the philosophy of pharmaceutical care, hence the need to assess knowledge, attitude and practice of pharmacists on MTM services as a standard of practice.

\section{Aim of the Study}

This study therefore aims at assessing the knowledge, attitude and practice of hospital pharmacists in selected hospitals in Delta state Nigeria on Medication Therapy Management services.

\section{Methods}

The study was carried out in seven hospitals selected from the three senatorial districts in Delta state: Delta North, Delta South and Delta Central. The hospitals include Federal Medical Centre, Asaba; Delta State Teaching Hospital, Oghara; Central Hospital, Warri; Central Hospital, Sapele; Central Hospital, Agbor; Central Hospital, Ughelli and General Hospital, Abraka. Notable among these settings are the Federal Medical Centre Asaba and the Delta state University Teaching Hospital (DELSUTH) Oghara which has 30 pharmacists and 15 intern pharmacists in its employment. Asaba is the capital of Delta State and has an estimated population of 149,603 (2006 census).

\section{Study design}

This was a cross-sectional, descriptive survey of was chosen as the means to assess the knowledge, attitude and practice of Medication Therapy Management of hospital pharmacists in Delta state. 


\section{Data collection}

The data collection method used was questionnaire design and personal interview. The framework of the Behavioural Pharmaceutical Care Scale (BPCS) (Odedina, 1996) was used for the development of the questionnaire. A well-structured 20 -item questionnaire with close-ended questions was designed and presented for the purpose of this study; with four proposed domains namely: social demographics, knowledge of Medication Therapy Management, attitude and direct patient care activities/current pharmacy practice of Medication Therapy Management. Overall, 115 copies of the validated questionnaires were distributed to hospital pharmacists in Asaba, Agbor, Abraka, Oghara, Sapele, Ughelli and Warri. Verbal informed consent was obtained from the respondents followed by a written introduction at the beginning of the questionnaire. All questions in the questionnaire were directed towards providing answers to the research objectives. In addition, personal interviews were also conducted.

\section{Pilot test}

The questionnaire was pre-tested at the General Hospital, Obiaruku and minor corrections were made thereafter. Relevant questions that were overlooked were added to adjust the questionnaire from 18 items to a 20-item questionnaire. An inclusion of my full name was made to the formal introduction at the beginning of the questionnaire for identification purposes and was face validated.

\section{Study population}

Inclusion criteria

The study was carried out on only hospital pharmacists practicing in the selected hospitals, including intern pharmacists.

\section{Exclusion criteria}

Pharmacy technicians, pharmacy students on Industrial Training (IT) and other health care professionals were excluded from this study.

\section{Data analysis}

The data obtained from respondents were analysed with Statistical Package for Social Sciences (SPSS) software version 20 for descriptive statistical and inferential analyses. Descriptive statistics such as frequency distribution, percentages, Fisher test of ANOVA and matched t-test were used to summarize the items within each domain. Relationships between the variables were tested using Pvalue. P-values were considered significant if less than 0.05 .

\section{Results}

Sociodemographic of hospital pharmacy

In this study, 115 questionnaires were administered to hospital pharmacists, 100 questionnaires were retrieved giving a response rate of $86.96 \%$.

Total sample population for this research was 100 hospital pharmacists. More female pharmacists were surveyed (52\%). Respondents were all pharmacists, most of them aged between 31 50 years, and had a basic Pharmacy degree of a BPharm or PharmD.

Only 19 of the pharmacists surveyed had an additional qualification (19\%). Therefore, of this 19 pharmacists, $15.8 \%$ of them had an M.Sc (Masters in Science) degree, $42.1 \%$ of them had an MPH (Masters in Public Health) degree, 26.3\% of them had FPCPharm (Fellow, Post-graduate College of Pharmacy), and $15.8 \%$ of them has an MPharm (Masters in Clinical Pharmacy) degree. Majority of the respondents had been in practice less than 10 years (Table 1).

\begin{tabular}{|l|c|}
\hline \multicolumn{1}{|c|}{ Characteristics } & N (\%) \\
\hline Gender & $48(48)$ \\
Female & $52(52)$ \\
\hline Age & \\
21 - 30 & $28(28)$ \\
31 - 40 & $34(34)$ \\
$41-50$ & $34(34)$ \\
Above 50 & $4(4)$ \\
Total & $100(100)$ \\
\hline Basic Pharmacy Qualifications & \\
B.Pharm & $76(76)$ \\
Pharm.D & $24(24)$ \\
Total & $100(100)$ \\
\hline Additional academic degree (s) & \\
M.Sc/MPharm & $6(31.4)$ \\
MPH & $8(42.1)$ \\
FPCPharm & $5(26.3)$ \\
Total & $19(100)$ \\
\hline Respondents' number of years in practice & \\
Below 10 years & $65(65)$ \\
10 - 20 years & $27(27)$ \\
20 - 30 years & $8(8)$ \\
Total & $(100)$ \\
\hline
\end{tabular}

Table 1: Sociodemographic of respondents. 
Knowledge of medication therapy management

The concept of Medication Therapy Management was well known by the respondents as $94 \%$ of the respondents had a good knowledge about MTM (Table 2). Almost half (47.65\%) of the respondents admit that they obtained the knowledge from pharmacy training; many of the respondents obtained knowledge of MTM from multiple sources such as through hospital presentations, journals, conferences and workshops; this is evident as total response exceeded 100 (Table 2). As respondents were also asked whether they have knowledge on Pharmaceutical care practice, almost all the respondents admit that there are similarities between Medication Therapy Management and Pharmaceutical Care.

\begin{tabular}{|l|c|}
\hline \multicolumn{1}{|c|}{ Items } & N (\%) \\
\hline Do you know about MTM? & $94(94)$ \\
\hline No & $6(6)$ \\
\hline $\begin{array}{l}\text { What were your source(s) of knowledge about } \\
\text { MTM? (Multiple options) }\end{array}$ & $81(47.65)$ \\
Pharmacy training & $35(20.59)$ \\
Journals & $13(7.65)$ \\
Conferences/Workshops & $41(24.12)$ \\
Hospital presentations & $100(100)$ \\
\hline Do you know about Pharmaceutical Care? & \\
Yes & \\
No & $98(98)$ \\
\hline $\begin{array}{l}\text { Are there any similarities between MTM and } \\
\text { Pharmaceutical Care? }\end{array}$ & \\
Yes & \\
No & \\
\hline
\end{tabular}

Table 2: Knowledge of medication therapy management.

Attitude towards medication therapy management

On assessing respondents' attitude towards Medication Therapy Management, majority of them (95\%) believe that MTM encourages collaboration and cooperation between pharmacists and other health care professionals, and most of them (76\%) think they should be remunerated when MTM services are given. Almost all of the hospital pharmacists said the provision of MTM services should be provided in hospital pharmacies in Nigeria. Majority (75\%) said they will be ready to be trained further on providing Medication Therapy Management in their practice settings.

Despite the positive attitude of respondents towards MTM, many claimed that they have barriers practicing it as shown in ta- ble 3. Highest occurring barriers include - lack of staff, lack of time, lack of adequate training and lack of resources (Table 3).

\begin{tabular}{|l|c|c|}
\hline \multicolumn{1}{|c|}{ Items } & Yes (\%) & No (\%) \\
\hline $\begin{array}{l}\text { Whether respondents believe medication } \\
\text { therapy management encourages collabora- } \\
\text { tion and cooperation between pharmacists } \\
\text { and other health care givers }\end{array}$ & $95(95)$ & $5(5)$ \\
\hline $\begin{array}{l}\text { Whether respondents think remuneration } \\
\text { is necessary for medication therapy man- } \\
\text { agement services }\end{array}$ & $76(76)$ & $24(24)$ \\
\hline $\begin{array}{l}\text { Whether respondents will encourage the } \\
\text { practice of medication therapy manage- } \\
\text { ment services in hospital pharmacies in } \\
\text { Nigeria }\end{array}$ & $97(97)$ & $3(3)$ \\
\hline $\begin{array}{l}\text { Whether respondents would like to be } \\
\text { trained on medication therapy manage- } \\
\text { ment services }\end{array}$ & $75(75.8)$ & $24(24.2)$ \\
\hline
\end{tabular}

Table 3a: Attitude of hospital pharmacists.

\begin{tabular}{|l|c|}
\hline \multicolumn{1}{|c|}{ Items } & N (\%) \\
\hline Lack of time & $65(21.7)$ \\
\hline Lack of knowledge & $43(14.4)$ \\
\hline Lack of training & $54(18.1)$ \\
\hline Lack of Communication skills & $21(7.0)$ \\
\hline Lack of resources & $48(16.1)$ \\
\hline Lack of adequate staff & $68(22.7)$ \\
\hline
\end{tabular}

Table 3b: Barriers to providing MTM services.

Practice of medication therapy management

The study objective was to assess current practice of the respondents and if it includes any of the core elements of MTM. On the assessment of whether direct Patient care is carried out by respondents, $89 \%$ of the respondents admit they use the patient medication record (PMR) to communicate and collaborate with other health care professionals to achieve optimal patient outcome. Almost half of the respondents (48\%) provide patients with medication - related action plan (MAP) to enable them track their progress towards health goals. Also, $92 \%$ of hospital pharmacists admit they ask patients questions to find out if they experience drug related problems and almost all of them (95\%) design and implement strategies to solve or prevent drug-related problems. More than half of the respondents (66\%) said they document services and interventions for evaluating patients' progress. And majority of the respondents follow up patients to evaluate their progress towards drug therapy goals (73\%). Details are shown in table 4.

Relationship between respondents' sociodemographic characteristics and their knowledge, attitude and practice of MTM

A regression analysis was done to test for statistically significant association between the variables. Result presented in table 


\begin{tabular}{|c|c|c|}
\hline Items & $\begin{array}{l}\text { Yes } \\
(\%)\end{array}$ & $\begin{array}{l}\text { No } \\
(\%)\end{array}$ \\
\hline $\begin{array}{l}\text { Whether respondents use the Patient Medica- } \\
\text { tion Record (PMR) to communicate and col- } \\
\text { laborate with other health care professionals to } \\
\text { achieve optimal patient outcomes }\end{array}$ & $\begin{array}{c}89 \\
(89)\end{array}$ & $\begin{array}{c}11 \\
(11)\end{array}$ \\
\hline $\begin{array}{l}\text { Whether respondents provide patients with a } \\
\text { Medication-Related Action Plan (MAP) to enable } \\
\text { them track progress towards health goals }\end{array}$ & $\begin{array}{c}48 \\
(48)\end{array}$ & $\begin{array}{c}52 \\
(52)\end{array}$ \\
\hline $\begin{array}{l}\text { Whether respondents ask patients questions to } \\
\text { find out if he/she might be experiencing drug- } \\
\text { related problems }\end{array}$ & $\begin{array}{c}92 \\
(92)\end{array}$ & $8(8)$ \\
\hline $\begin{array}{l}\text { Whether respondents design and implement } \\
\text { strategies to resolve or prevent drug-related } \\
\text { problems }\end{array}$ & $\begin{array}{c}95 \\
(95)\end{array}$ & $5(5)$ \\
\hline \multicolumn{3}{|l|}{ Additional qualifications } \\
\hline $\begin{array}{l}\text { Whether respondents document services and } \\
\text { interventions performed in a manner appropri- } \\
\text { ate for evaluating patient's progress }\end{array}$ & $\begin{array}{c}66 \\
(66)\end{array}$ & $\begin{array}{c}34 \\
(34)\end{array}$ \\
\hline $\begin{array}{l}\text { Whether respondents follow up patients to } \\
\text { evaluate progress towards drug therapy goals }\end{array}$ & $\begin{array}{c}73 \\
(73)\end{array}$ & $\begin{array}{c}27 \\
(27)\end{array}$ \\
\hline
\end{tabular}

\begin{tabular}{|l|c|c|c|}
\hline \multicolumn{1}{|c|}{ Characteristics } & $\begin{array}{c}\text { Knowledge } \\
\text { F } \\
\text { (p-value) }\end{array}$ & $\begin{array}{c}\text { Attitude } \\
\text { F } \\
\text { (p-value) }\end{array}$ & $\begin{array}{c}\text { Practice } \\
\text { F } \\
\text { (p-value) }\end{array}$ \\
\hline Gender of respondents & $\begin{array}{c}1.848 \\
(0.163)\end{array}$ & $\begin{array}{c}0.039 \\
(0.961)\end{array}$ & $\begin{array}{c}1.512 \\
(0.226)\end{array}$ \\
\hline Age of respondents & $\begin{array}{c}1.362 \\
(0.259)\end{array}$ & $\begin{array}{c}1.350 \\
(0.263)\end{array}$ & $\begin{array}{c}3.078 \\
(0.031)^{*}\end{array}$ \\
\hline $\begin{array}{l}\text { Qualification to practice } \\
\text { (First degree in Pharmacy) }\end{array}$ & $\begin{array}{c}2.198 \\
(0.116)\end{array}$ & $\begin{array}{c}0.808 \\
(0.449)\end{array}$ & $\begin{array}{c}6.249 \\
(0.003)^{*}\end{array}$ \\
\hline $\begin{array}{l}\text { Additional qualifications } \\
\text { (Post-graduate degree) }\end{array}$ & $\begin{array}{c}0.572 \\
(0.687)\end{array}$ & $\begin{array}{c}5.987 \\
(0.005)^{* *}\end{array}$ & $\begin{array}{c}7.383 \\
(0.002)^{* *}\end{array}$ \\
\hline $\begin{array}{l}\text { Level of significance set at p } \\
<0.05\end{array}$ & & & \\
\hline
\end{tabular}

Table 5a: Inferential statistics showing relationship between socio demographic characteristics and knowledge, attitude and practice of MTM by respondents (hospital pharmacists).

$\mathrm{P}<0.05^{*}$ : Significant relationship between variables.

$\mathrm{P}<0.05^{* *}$ : Highly significant relationship between variables.

Table 4: Practice of medication therapy management.

$5 a$ shows there is an association between age of respondents and practice of MTM ( F = 3.078, $\mathrm{P}=.03)$; respondents' qualifications and practice of MTM $(\mathrm{F}=6.249, \mathrm{p}<.01)$; and respondents with additional qualification and their attitude towards MTM. This implies that as hospital pharmacists update their professional qualifications, their attitude toward MTM also changes positively. The result also reveals that the practice of Medication Therapy Management varies among practitioners in terms of their age $(F=3.078$, $\mathrm{P}<0.05)$, level of qualification $(\mathrm{F}=6.249, \mathrm{P}<0.01)$ and additional qualifications $(\mathrm{F}=7.383, \mathrm{P}<0.01)$. This implies that as respondents' ages and qualifications change, their practicing skills also changes positively (Details in table $5 \mathrm{a}$ ).

An ANOVA result shown in table 5b, indicates that there is no statistically significant difference between respondents' knowledge, attitude and practice of MTM. In other words, they were equally rated in knowledge, attitude and practice.

\begin{tabular}{|c|c|c|c|c|c|c|}
\hline \multicolumn{7}{|l|}{ Summary } \\
\hline Groups & Count & Sum & Average & Variance & & \\
\hline Knowledge & 4 & 5.98 & 1.495 & $\begin{array}{c}0 . \\
496145\end{array}$ & & \\
\hline Attitude & 4 & 8.184 & 2.046 & $\begin{array}{c}7 . \\
192197 \\
\end{array}$ & & \\
\hline Practice & 4 & 18.222 & $\begin{array}{c}4 . \\
5555 \\
\end{array}$ & $\begin{array}{c}7 . \\
436199\end{array}$ & & \\
\hline \multicolumn{7}{|l|}{ ANOVA } \\
\hline $\begin{array}{l}\text { Source of } \\
\text { Variation }\end{array}$ & SS & df & MS & $\mathbf{F}$ & P-value & F crit \\
\hline $\begin{array}{l}\text { Between } \\
\text { Groups }\end{array}$ & \begin{tabular}{|c|}
21. \\
29047
\end{tabular} & 2 & $\begin{array}{c}10 . \\
64523\end{array}$ & $\begin{array}{c}2 . \\
111516\end{array}$ & $\begin{array}{c}0 . \\
177052\end{array}$ & $\begin{array}{c}4 . \\
256495\end{array}$ \\
\hline $\begin{array}{l}\text { Within } \\
\text { Groups }\end{array}$ & \begin{tabular}{|c|}
45. \\
37362 \\
\end{tabular} & 9 & $\begin{array}{c}5 . \\
041514\end{array}$ & & & \\
\hline Total & \begin{tabular}{c|}
66. \\
66409 \\
\end{tabular} & 11 & & & & \\
\hline
\end{tabular}

Table 5b: Inferential statistics (ANOVA) to test for significant difference between knowledge, attitude and practice of hospital pharmacists on MTM.

There was no significant difference between the knowledge, attitude and practice of the pharmacists on MTM, F $(2,9)=2.11$, $\mathrm{p}=0.18$.

Citation: Akonoghrere Rita., et al. "Knowledge, Attitude and Practice of Medication Therapy Management among Hospital Pharmacists in Delta State, Nigeria". Acta Scientific Pharmaceutical Sciences 4.8 (2020): 118-126. 


\section{Discussion}

Majority of the respondents had only the basic qualifying degree to practice as a pharmacist - B.Pharm qualification; very few of them had additional qualifications in addition to their first degree. This however did not indicate low interest in furthering their training on Medication Therapy Management. Majority of the respondents had practice experience less than 10 years which did not limit their knowledge of MTM as all the respondents had prior knowledge of pharmaceutical care and its relationship to MTM, which shows that it is a rapidly growing trend. The knowledge of Pharmaceutical Care is widespread and this is supported by the fact that all respondents in this study had knowledge of Pharmaceutical Care. This is in contrast with a study done on community pharmacists in Kaduna state, Nigeria, where 97.5\% had knowledge deficit of Pharmaceutical Care concepts but there was a positive attitude to its practice (Ma'aji, 2014).

Majority of the respondents (98\%) admit there are similarities with MTM and Pharmaceutical Care. This is in consonance with the findings of Zachariah., et al. [9] delineating the relationship, including similarities between MTM and Pharmaceutical Care. Medication Therapy Management is offered as an all-encompassing model that incorporates the philosophy of Pharmaceutical Care, techniques of patient counselling, and disease management in an environment that facilitates the direct collaboration of patients, pharmacists and other health professionals [10]. About half of MTM providers in United States in 2007 reported that they were contracted with programs to provide their services; a low number (35\%) of these respondents indicated that these contracts provided a positive return on investment (ROI) (Schommer., et al. 2007), indicating that remuneration for provision of MTM services could be a motivation for hospital pharmacists to include MTM as part of the routine services they provide, similar to the findings in this study.

More than average number of respondents (75\%) said they will be ready to be trained further on MTM. This is consistent with a study carried out on Texas pharmacists where $74 \%$ of the respondents intended to become MTM providers and 78\% where interested in additional training [11]. In a study carried out on fourth-year students completing an advanced pharmacy practice experience (APPE) in MTM, the results showed that those students had signifi- cantly higher self-efficacy. This shows that further training on MTM is beneficial to the pharmacist and the society at large [12].

Majority of the respondents had a positive attitude towards providing MTM. This shows strong willingness to practice this model of pharmaceutical care. Despite this, all the respondents believed there were substantial barriers to its implementation. This is in accordance with a 2005 study of pharmacists' intention to provide MTM services, where pharmacists complained of barriers [13]. Also, in a 2010 study which attempted to explore the perceived barriers to providing MTM services, the authors found that comfort level in provision of services to patients was the most important predictor of whether a pharmacist would be likely to work in a hospital pharmacy that provided MTM services [14].

On assessing the core elements of MTM, slightly more than half of the respondents reported that they do not provide patients with medication - related action plan (MAP) to enable them track their progress towards health goals, similar to a study carried out on Texas pharmacists, where it was discovered that they were confident in providing Medication Therapy Review (MTR), creating a Personal Medication Record (PMR) and performing intervention and referral but were only somewhat confident in creating a Medication Action Plan [11]. Majority of the hospital pharmacists in this study believed that MTM encourages collaboration and cooperation between pharmacists and health care givers. There is evidence to support that greater collaboration between pharmacists and physicians can improve patient care, and Medication Therapy Review (MTR) is an example of how pharmacists can offer their assistance. Several randomised trials have shown improvements in prescribing, and reduced healthcare use and medication costs following MTRs in patients with hypertension, hyperlipidaemia and diabetes [15]. Medication therapy reviews after discharge from hospital have reduced morbidity and mortality in patients with heart failure [16].

Most of the respondents in this study admit that they implement strategies to solve or prevent drug-related problems similar to what obtains in other climes where hospital pharmacists have a role to provide multiple risk management strategies to improve medication safety; the role focuses on interventions to high-risk 
patient groups and disease states and use practice information technology systems to detect potential safety problems [17].

Slightly more than half of the respondents said they document services and interventions for evaluating patients' progress which is in contrast to findings in a study carried out on Texas based pharmacists where respondents disagreed or were neutral about having adequate documentation systems for MTM services provided [11].

Most of the respondents in this study follow up on the patient's progress on adherence. This is similar to results obtained from a study on maximizing MTM services through a referral initiative where the percentage of MTM follow-up encounters significantly increased over a period of time (Imberg., et al. 2012). This is very important in assessing patient adherence to medication regimen.

Also, from this study, as the respondents update their professional qualifications and experience, their attitude towards MTM changed. This can be due to increase in knowledge gained through educational training. The implication of this is that as the practitioners gain higher knowledge on MTM, and provide MTTM services, their attitude towards it also improves. This is in contrast to a study of pharmacist's attitude towards Pharmaceutical Care, where the attitude ratings were inversely proportional to the level of professional experience, with pharmacists having less experience showing better attitude towards pharmaceutical care [3,18-36].

\section{Conclusion}

This study has shown that hospital pharmacists in Delta state have a good knowledge of MTM proving that the trend of adopting it as a practice model is on the rise. Hospital pharmacists in Delta state have a favourably high attitude towards providing MTM services irrespective of the barriers they face in practicing it in the hospital. They expressed concerns about lack of adequate staffing, resources and time. The attitude ratings vary with the level of professional experience and educational qualifications, with pharmacists having more experience showing more positive attitude. The pharmacists incorporated the core elements of MTM favourably, except the use of Medication Therapy Review (MTR). Medication Therapy Management service providers would benefit from a better understanding of which core components really matter. This research has shown that the hospital pharmacists in Delta State practice MTM and are willing to be trained further in order to improve clinical, economic and humanistic outcomes for patients. This study will help in future research into MTM practice in Nigeria and adopting it as a service in all hospital pharmacies.

\section{Conflict of Interest}

The authors have none to declare.

\section{Bibliography}

1. Bluml BM. "Definition of medication therapy management: development of profession wide consensus". Journal of the American Pharmacists Association 45 (2005): 566-572.

2. Hepler CD and Strand L M. "Opportunities and responsibilities in Pharmaceutical Care". The American Journal of HealthSystem Pharmacy 47 (1990): 533-543.

3. Oparah AC. "Essentials of Pharmaceutical Care". All Deals Investment Company Limited 11 (2010): 83-89.

4. Baltazar A. What is Medication Therapy Management? (2014).

5. Medication Therapy Management in Pharmacy Practice: Core Elements of an MTM Service Model. Version 2.0. Washington, DC: American Pharmacists Association; National Association of Chain Drug Stores Foundation (2008): 7-13.

6. Wagner EH. "Chronic disease management: What will it take to improve care for chronic illness?" Effective Clinical Practice 1.1 (1998): 2-4.

7. Garrett D and Bluml B. "Patient self-management program for diabetes: first- year clinical, humanistic, and economic outcomes". Journal of the American Pharmacists Association 45 (2005): 130-137.

8. American Pharmacist Association. "National Association of Chain Drug Stores Foundation". Journal of the American Pharmacists Association 48.3 (2008): 341-353.

9. Zachariah S., et al. "Rational Drug Use, Formulary Management, Pharmaceutical Care/Medication Therapy Management/Pharmacists Patient Care Process". Clinical Pharmacy Education, Practice and Research; Elsevier Publication 5 (2019): 59-77. 
10. McGivney SM., et al. "Medication Therapy Management: Its relationship to patient counselling, disease management and Pharmaceutical Care". Journal of the American Pharmacists Association 47 (2007): 620-628.

11. Moczygemba LR., et al. “Texas pharmacists' opinions about and plans for provision of Medication Therapy Management services". Journal of the American Pharmacists Association 48.1 (2008): 38-45.

12. Urmie JM., et al. "Pharmacy students' knowledge of the Medicare drug benefit and intention to provide Medicare Medication Therapy Management services". American Journal of Pharmaceutical Education 71.3 (2007): 41.

13. Herbert KE., et al. "Prediction of pharmacist intention to provide Medicare Medication Therapy Management services using the theory of planned behaviour". Research in Social and Administrative Pharmacy 2.3 (2006): 299-314.

14. Blake KV and Madhavan SS. "Perceived barriers to provision of Medication Therapy Management services (MTMS) and the likelihood of a pharmacist to work in a pharmacy that provides MTMS”. Annals of Pharmacotherapy 44.3 (2010): 424-431.

15. Lenaghan E., et al. "Home-based medication review in a high risk elderly population in primary care -the POLYMED randomised controlled trial". Age and Ageing 36 (2007): 292-297.

16. Ponniah A., et al. "Pharmacists' role in the post-discharge management of patients with heart failure: a literature review". Journal of Clinical Pharmacology and Therapeutics 32 (2007): 343-352.

17. Ackerman E., et al. "Pharmacists in general practice - a proposed role in the multidisciplinary team". Australian Family Physician 39 (2010): 163-164.

18. Berger BA. "Interacting with physicians". In: Communication Skills for Pharmacists. $2^{\text {nd }}$ edition. Washington, DC: American Pharmacists Association (2005): 131-139.
19. Bunting BA and Cranor CW. "The Asheville Project: long-term clinical, humanistic, and economic outcomes of a community-based medication therapy management program for asthma". Journal of the American Pharmacists Association 46 (2003): 133-147.

20. Cranor CW., et al. "The Asheville Project: long-term clinical and economic outcomes of a community pharmacy diabetes care program". Journal of the American Pharmacists Association 43 (2003): 173-190.

21. Effective Health Care program. Medication Therapy Management (2013).

22. Ernst FR and Grizzle AJ. "Drug-related morbidity and mortality: Updating the cost-of illness model". Journal of the American Pharmacists Association 41 (2001): 192-199.

23. Jameson J., et al. "The impact of a pharmacotherapy consultation on the cost and outcome of medical therapy". The Journal of Family Practice 41.5 (1995): 469-472.

24. Joan Dan Vanzo., et al. "Medication Therapy Management Services: A Critical Review". American Pharmacists Association (2005): 9-10.

25. Johnson JA and Bootman JL. "Drug related morbidity and mortality and the economic impact of Pharmaceutical Care". American Journal of Health-System Pharmacy 54 (1997): 554-558.

26. Johnson JA and Bootman JL. "Drug related morbidity and mortality: A cost of Illness Model". Archives of General Internal Medicine 155 (1995): 1949-1956.

27. Lipton HL., et al. "The impact of clinical pharmacists' consultations on physicians' geriatric drug prescribing". Med Care 30 (1992): 646-658.

28. Medicare Prescription Drug, Improvement and Modernization Act of Public Law 108 (2003): 173.

29. Plumridge RJ and Worjnar-Horton RE. "A review of the pharmacoeconomics of pharmaceutical care". Pharmacoeconomics 14.2 (1998): 175-189. 
30. Rovers J., et al. "The case for pharmaceutical care”. In: A Practical Guide to Pharmaceutical Care. $2^{\text {nd }}$ edition. Washington, DC: American Pharmacists Association (2003): 3-4.

31. Rupp MT. "Value of the community pharmacists' interventions to correct prescribing errors". 26 (1992): 1580-1584.

32. Schultz H., et al. "Patient-perceived value of Medication Therapy Management (MTM) services: a series of focus groups (2012): 5-6.

33. Schumock GT., et al. "Evidence of the economic benefit of clinical pharmacy services: 1996-2000". Annals of Pharmacotherapy 23 (2003): 113-132.

34. Smith W. "Excellence in the management of clinical pharmacy services". The American Journal of Health-System Pharmacy 45 (1988): 319-325.

35. Tomechko MA., et al. " $Q$ and A from the pharmaceutical care project in Minnesota”. American Pharmaceutical 354 (1995): 30-39.

36. Zierler-Brown S., et al. "Clinical Documentation for Patient Care: Models, Concepts, and Liability Considerations for Pharmacists". American Journal of Health-System Pharmacy 64 (2007): 1851-1858.

\section{Assets from publication with us}

- Prompt Acknowledgement after receiving the article

- Thorough Double blinded peer review

- Rapid Publication

- Issue of Publication Certificate

- High visibility of your Published work

Website: www.actascientific.com/

Submit Article: www.actascientific.com/submission.php

Email us: editor@actascientific.com

Contact us: +919182824667 